Research paper

\title{
Characterization of the galactono-1,4-lactone dehydrogenase from pepper fruits and its modulation in the ascorbate biosynthesis. Role of nitric oxide ${ }^{\text {is }}$
}

\author{
Marta Rodríguez-Ruiz ${ }^{\mathrm{a}, 1}$, Rosa M. Mateos ${ }^{\mathrm{b}, 1}$, Verónica Codesido ${ }^{\mathrm{c}}$, Francisco J. Corpas ${ }^{\mathrm{a}}$, \\ José M. Palma ${ }^{\mathrm{a}, *}$

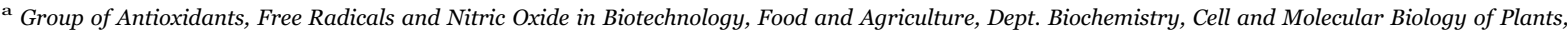 \\ Estación Experimental del Zaidín, CSIC, C/ Profesor Albareda, 1, 18008 Granada, Spain \\ b University Hospital Puerta del Mar, Avenida Ana de Viya, 21, Cádiz 11009, Spain \\ c Phytoplant Research S.L, Rabanales 21 - The Science and Technology Park of Córdoba, C/ Astrónoma Cecilia Payne, Edificio Centauro, módulo B-1, 14014 \\ Córdoba, Spain
}

\section{A R T I C L E I N F O}

Keywords:

Ascorbate metabolism

Cloning

Galactono-1,4-lactone dehydrogenase

Nitric oxide

Pepper fruit ripening

Reactive nitrogen species

\begin{abstract}
A B S T R A C T
Pepper fruit is one of the highest vitamin C sources of plant origin for our diet. In plants, ascorbic acid is mainly synthesized through the L-galactose pathway, being the L-galactono-1,4-lactone dehydrogenase (GalLDH) the last step. Using pepper fruits, the full GalLDH gene was cloned and the protein molecular characterization accomplished. GalLDH protein sequence (586 residues) showed a 37 amino acids signal peptide at the Nterminus, characteristic of mitochondria. The hydrophobic analysis of the mature protein displayed one transmembrane helix comprising 20 amino acids at the $\mathrm{N}$-terminus. By using a polyclonal antibody raised against a GalLDH internal sequence and immunoblotting analysis, a $56 \mathrm{kDa}$ polypeptide cross-reacted with pepper fruit samples. Using leaves, flowers, stems and fruits, the expression of GalLDH by qRT-PCR and the enzyme activity were analyzed, and results indicate that GalLDH is a key player in the physiology of pepper plants, being possibly involved in the processes which undertake the transport of ascorbate among different organs.

We also report that an NO (nitric oxide)-enriched atmosphere enhanced ascorbate content in pepper fruits about $40 \%$ parallel to increased GalLDH gene expression and enzyme activity. This is the first report on the stimulating effect of NO treatment on the vitamin C concentration in plants. Accordingly, the modulation by NO of GalLDH was addressed. In vitro enzymatic assays of GalLDH were performed in the presence of SIN-1 (peroxynitrite donor) and $S$-nitrosoglutahione (NO donor). Combined results of in vivo NO treatment and in vitro assays showed that NO provoked the regulation of GalLDH at transcriptional and post-transcriptional levels, but not post-translational modifications through nitration or $S$-nitrosylation events promoted by reactive nitrogen species (RNS) took place. These results suggest that this modulation point of the ascorbate biosynthesis could be potentially used for biotechnological purposes to increase the vitamin $\mathrm{C}$ levels in pepper fruits.
\end{abstract}

\section{Introduction}

Ascorbic acid (vitamin C) is one of the most powerful antioxidants synthesized in the majority of living beings, excepting primates (including humans), guinea pigs, bats and some birds $[32,55,74,79,96,97]$. Within plant cells, this molecule is ubiquitous and can be detected in many subcellular loci, although it is also found in the apoplast $([46,47,79,80,88])$. As an antioxidant, it can directly interact with hydroxyl radicals $(\cdot \mathrm{OH})$, superoxide radicals $\left(\mathrm{O}_{2}^{--}\right)$, hydrogen peroxide $\left(\mathrm{H}_{2} \mathrm{O}_{2}\right)$ and singlet oxygen [21,22,44,89]. Furthermore, ascorbate is an electronic donor for the ascorbate peroxidase (APX; EC. 1.11.1.11) activity to remove the hydrogen peroxide, either as an individual reaction but also as the first stage of the ascorbate-glutathione cycle in plants (Foyer-Halliwell-Asada path-

\footnotetext{
Note: Sequence data from this article have been deposited in the EMBL/GenBank data libraries under accession number AY547352 and AY572427 for the Capsicum annuum L GalLDH complete cDNA and actin mRNA, partial cDNA, respectively.

* Corresponding author.

E-mail addresses: marta.rodriguez@eez.csic.es (M. Rodríguez-Ruiz), mateosrosa@hotmail.com (R.M. Mateos), v.codesido@phytoplant.es (V. Codesido), javier.corpas@eez.csic.es (F.J. Corpas), josemanuel.palma@eez.csic.es (J.M. Palma).

${ }^{1}$ These authors equally contributed to this work.
} 
way). This metabolic route, besides APX, involves the participation of the mondehydroascorbate reductase (MDAR; EC 1.6.5.4), the dehydroascorbate reductase (DAR; EC 1.8.5.1), and the glutathione reductase (GR; EC 1.8.1.7), in a process which needs the continuous provision of NADPH [27,35,39,53,8,80,91]. Moreover, ascorbate is implicated in the regeneration of $\alpha$-tocopherol and in the xanthophylls cycle, and it serves as a co-factor for many enzymes [28,33,7].

At physiological level, it has been found that, in plants, ascorbic acid participates in the mechanisms of cell signaling playing a role in the responses to pathogens through a complex signal transduction network which implies the modulation of the content of the signal molecules salicylic acid, abscisic acid, ethylene and gibberellins $[101,11,22]$. Moreover, ascorbic acid has been reported to be linked to hormone synthesis, gene expression, cell division and growth, flowering, developmental senescence, programmed cell death or apoptosis, and stomata movement of guard cells, among others $[19,38,64,79]$. Overall, this multiplicity of functions makes ascorbate to be considered as a redox buffer in the plant cell $[38,91]$. Thus, in a very recent report, it has been postulated that ascorbate buffers the important metabolic changes which occur at ripening of pepper acting as a preservative to expand the shelf life of fruits [80].

The biosynthesis of ascorbic acid in plants has been the aim of many investigations, basically in species destined for human consume. Thus, although the main pathways involved in such event have been well established so far [100,103,23,52,64,90,97], transcription and expression studies were achieved during last years in order to understand the complex regulation of those routes $[104,107,108,29,49,62,65]$.

Three pathways for the ascorbic acid biosynthesis were initially proposed in plants: one via L-galactose (the L-galactose pathway) [99]; another one from myo-inositol [51,66,67]; and a third one through Lgalacturonic acid [2]. An alternative L-gulose pathway sharing some stages with that occurring in animal cells, and implying the involvement of an L-gulono-1,4-lactone oxidase as the last step of this metabolic channel, has been also hypothesized (see reviews in Wolucka et al., 2007 and [64]). Both the linear L-galactose pathway and the L-gulose pathway were lately associated to a VTC2 cycle (GDPL-galactose phosphorylase, GGP; VTC2 gene) which provides phosphorylated galactose and phosphorylated mannose, respectively, for the final synthesis of ascorbate ([100,103,57,63,64]).

Thus far, the most consensual route for ascorbate biosynthesis is the L-galactose pathway, with the final step requiring the oxidation of L-galactono-1,4-lactone (GalL) to ascorbic acid, in a reaction which is catalyzed by the L-galactono-1,4-lactone dehydrogensase (GalLDH; EC. 1.3.2.3). This reaction is not coupled to any coenzyme pair, so the electrons from the GalL are directly transferred to the cytochrome $c$ located at the inner mitochondrial membrane [12,45,73,92,99]. cDNAs encoding GalLDH have been characterized from cauliflower, sweet potato, strawberry, tomato, tobacco, Arabidopsis, peach, and rosier, among others, and the theoretical topology and structure have been accordingly proposed ([105,48,49,77,94,6]).

GalLDH has been depicted to contain membrane-spanning regions, so this peculiarity and its electron-transferring role indicate that this protein should be associated to the intermembrane space. Thus, GalLDH has been reported as an integral protein of the mitochondrial inner membrane [12,48,87], but some other authors have suggested that GalLDH is a peripheral protein $[61,84]$. More recently, this protein was described to form part of the mitochondrial complex I in Arabidopsis [84], where it seems that, besides donating electrons to the transfer chain, it also functions as an assembly factor [85]. This step of the GalLDH seems to be an important regulatory point in the ascorbate biosynthetic pathway and in the accumulation of ascorbic acid, as it has been thoroughly reported ([82,93,94,6,109,60,65,98]). Recently it has been reported that pepper fruits is one of the richest vitamin $\mathrm{C}$ sources of plant origin in our diet, and an important role of ascorbate in the fruit physiology was proposed [80]. Thus, the investigation of the modulation of the ascorbate synthesis in plant crops with agronomic interest such as pepper is an issue which deserves our attention.

In the latest years, it has been postulated that, in plants, nitric oxide (NO) and its derivatives called reactive nitrogen species (RNS), including $S$-nitrosoglutathione (GSNO) and peroxynitrite $\left(\mathrm{ONOO}^{-}\right)$, among others, are involved in important and vital physiological issues such as the defence response to both biotic and abiotic, as a regulators of growth, development, immunity and environmental interactions, in processes such as germination, flower setting and flower development, growth and development of roots, senescence, and very recently, in delaying ripening of fruits $[18,59]$. In many of those cases, it has been reported that these roles of RNS are mediated through post-translational modifications (PTMs) of proteins which, then, modulate the processes indicated above by mechanisms of cellular signaling. Most of these RNS-mediated PTMs include events such nitrosylation of thiol and amine groups, and nitration of tyrosine and other amino acids [18]. To our knowledge, no data are available on the modulation of the ascorbate biosynthesis in crop species by NO and other RNS.

In this work, due to the relevance of ascorbate in the metabolism of pepper fruits [80], where the GalLDH might then play an important role in the physiology throughout the plant life cycle, the full characterization of the GalLDH from fruits was achieved. The full length cDNA clone of the GalLDH was accomplished and its molecular and immunological properties were studied. The enzyme activity and gene expression of GalLDH in leaves, flowers, stems and fruits were also determined. Besides, the modulation of the ascorbate metabolism in pepper fruits through the regulation of the GalLDH by distinct RNS was investigated, and the obtained results on that issue provide evidence which may explain the increased ascorbate levels during fruit ripening.

\section{Materials and methods}

\subsection{Plant material and growth conditions}

Pepper (Capsicum annuum L.) fruits, leaves, flowers and stems were obtained from plants grown in experimental glass-covered greenhouse (Syngenta Seeds, Ltd., El Ejido, Spain), with optimal nutrients supplementation applied on rockwood as substrate. Fresh fruits from the same plants at distinct ripening stages (immature green and mature red phenotypes) were used for this study. When treatment of pepper fruits with NO was carried out, experiments were performed according to [18]. Briefly, pepper fruits at a breaking-point stage were subjected to an NO-enriched atmosphere (5 ppm) in a hermetic box for $1 \mathrm{~h}$. This condition was set by the use of a Nitric Oxide Meter (Environmental Sensors Co., Boca Raton, FL, USA). Afterwards, fruits were maintained under room temperature for 10 days and, finally, they were processed for diverse analyses such as determination of ascorbate content, and enzyme activity and gene expression of the L-galactono-1,4-lactone dehydrogenase. Fruits at breaking point were used to investigate the modulation of GalLDH during the ripening process and not those at steady stages, either green or red, as indicated above. Fruits harvested at immature green stage do not ripe, so they never shift into red colour, and mature red fruits do not ripe any longer but senesce after several weeks. Thus, breaking point fruits are the only material where a dynamic process such as ripening (colour shift takes 3-8 days in pepper depending on the cultivar) can be monitored. In our experimental conditions, fruits were subjected to NO treatment at the breaking point stage, while sampling for further assays (ascorbate and GalLDH) of both treated and untreated fruits was done when they had already ripened and were red (10 days after treatment; Supplementary Fig. 1). In previous studies, it was proved that NO delayed ripening of pepper fruits with untreated fruits ripening after 3 days whereas NO-treated ones did several days later [18]. 


\subsection{Crude extracts of pepper fruits}

All operations were performed at $0-4{ }^{\circ} \mathrm{C}$. Plant materials for enzymatic analyses were ground in a mortar and a pestle in the presence of extraction buffer $[50 \mathrm{mM}$ Tris- $\mathrm{HCl} \mathrm{pH}$ 7.5, $0.1 \mathrm{mM}$ EDTA, $0.1 \%(\mathrm{v} / \mathrm{v})$ Triton X-100, 10\% (v/v) glycerol and $2 \mathrm{mM}$ DTT] in a $1: 2(\mathrm{p} / \mathrm{v})$ ratio and further filtered through two layers of nylon cloth. In the case of fruits, $100 \mathrm{mM}$ Tris- $\mathrm{HCl}, \mathrm{pH} 7.5$ buffer and the ratio 1:1 was used instead. The homogenates were then centrifuged at $27,000 \mathrm{~g}$ for $25 \mathrm{~min}$ and $4{ }^{\circ} \mathrm{C}$ and supernatants were used for the activity assays.

\section{3. $R N A$ isolation and full-length cDNA cloning of the GalLDH}

Total RNA was isolated from pepper fruits, leaves, flowers and stems with the Trizol $^{\circledR}$ Reagent (Gibco BRL) as described in the manufacturer's manual, and RNA was quantified spectrophotometrically. Two $\mu \mathrm{g}$ of total RNA were used as a template for the reverse transcriptase (RT) reaction. It was added to a mixture containing $1.5 \mathrm{mM}$ dNTPs, $1.6 \mu \mathrm{g}$ polydT $\mathrm{T}_{23}$ primer, $1 \mathrm{X}$ RT-buffer $(25 \mathrm{mM}$ Tris$\mathrm{HCl} \mathrm{pH} \mathrm{8.3,} 5 \mathrm{mM} \mathrm{MgCl}_{2}, 50 \mathrm{mM} \mathrm{KCl}, 2 \mathrm{mM}$ DTT), 0.9 U Rnasin ribonuclease inhibitor and $20 \mathrm{U}$ AMV reverse transcriptase (FINNZYMES). The reaction was carried out at $42^{\circ} \mathrm{C}$ for $40 \mathrm{~min}$, followed by a $5 \mathrm{~min}$ step at $98^{\circ} \mathrm{C}$, and then by cooling to $4^{\circ} \mathrm{C}$ for $10 \mathrm{~min}$. Then, the polymerase chain reaction (PCR) was as follows: $1 \mu \mathrm{l}$ of the produced cDNA was added to $250 \mu \mathrm{M}$ dNTPs, $2.5 \mathrm{mM} \mathrm{MgCl}_{2}, 1 \mathrm{X}$ PCR buffer, $0.5 \mathrm{U}$ of HotMaster Tap DNA Polymerase (Eppendorf) and $0.5 \mu \mathrm{M}$ of each primer (F-GalLDH, 5'-TTACTCTTCAGAACTTTGC-3'; R-GalLDH, 5'-GGATTGCATGTCACAACCAC-3') in a final volume of 20 $\mu$ l. Reactions were carried out in a Hybaid thermo-cycler (Ashford, UK). A first step of $2 \mathrm{~min}$ at $94^{\circ} \mathrm{C}$ was followed by 36 cycles of $20 \mathrm{~s}$ at $94{ }^{\circ} \mathrm{C}, 20 \mathrm{~s}$ at $55^{\circ} \mathrm{C}$ and $1 \mathrm{~min}$ at $65^{\circ} \mathrm{C}$ with a final extension of $10 \mathrm{~min}$ at $65^{\circ} \mathrm{C}$. Amplified PCR products were detected after electrophoresis in $1 \%$ agarose gels stained with ethidium bromide. The PCR reaction was loaded on a $1 \%$ agarose gel and the visualized bands were cut and extracted from the gel (GFX PCR DNA and Gel Band Purification Kit, Amersham Biosciences). The purified fragments were cloned into the pGEM-T Easy vector (Promega). Finally, a partial cDNA for the GalLDH with the carboxylic terminal was obtained confirmed by sequencing.

Based on the nucleotide sequence obtained, 5'-extension of the cDNA clone was performed using the rapid amplification of cDNA ends (RACE) technique [41] with a commercial kit (BD SMART ${ }^{\mathrm{TM}}$ RACE cDNA Amplification, BD Bioscience). To obtain the cDNA with the fragment 5'BD SMART, the manufacturer's protocol was followed. RNA $(0.7 \mu \mathrm{g})$, obtained from red fruits, was added to $1.2 \mu \mathrm{M}$ primer 5 'CDS (polyT), $1.2 \mu \mathrm{M}$ oligonucleotide BD SMART II ${ }^{\mathrm{TM}} \mathrm{A}$ in $5 \mu \mathrm{l}$. After incubation at $70{ }^{\circ} \mathrm{C}$ for $2 \mathrm{~min}$ and further $2 \mathrm{~min}$ at $4{ }^{\circ} \mathrm{C}$, the mix was added $1 \mathrm{X}$ First Strand buffer, $2 \mathrm{mM}$ DTT, $1 \mathrm{mM}$ dNTPs and $1 \mu \mathrm{l}$ BD PowerScript $^{\mathrm{TM}}$ Reverse Transcriptase (Bioscience), and incubated $90 \mathrm{~min}$ at $42^{\circ} \mathrm{C}$ in a thermo-cycler PCR Express (Hybaid). Finally, $100 \mu \mathrm{l}$ Tricine-EDTA buffer were added to the RT-RACE product with further incubation at $72^{\circ} \mathrm{C}$ for $7 \mathrm{~min}$. For further cloning of the 5 'cDNA copy PCR-RACE was carried out in a total reaction $(50 \mu \mathrm{l})$ containing BD Advantage 2 buffer and BD Advantage 2 Polymerase Mix, $0.2 \mathrm{mM}$ dNTP, $2.5 \mu \mathrm{l}$ RT-RACE product, properly diluted, UPM $1 \mathrm{X}$ oligonucleotide and $0.4 \mathrm{mM}$ primer (5'GGTAACCAGTTTCATGCTTATGACTTGCTC-3') designed as antisense gene.

Amplified fragments were cloned into plasmid pGEM $^{\circledR}-\mathrm{T}$ Easy (Promega). Nucleotide sequences were analyzed with Omiga 2 (Oxford Molecular) and ABIview. The full-length cDNA for the GalLDH in Capsicum annuum L. were deposited in the databank with accession number AY547352 (https://www.ncbi.nlm.nih.gov).

\subsection{Sequence analysis, databases searches, subcellular localization predictions and primers design}

Blast searches were made in the National Center for Biotechnology Information internet site (http://www. ncbi.nlm.nih.gov/). Alignments were performed using OMIGA (2.0) and CLUSTALW (http://www.ebi. ac.uk/) platforms. Primers design was done with OMIGA (2.0). Localization predictions were achieved with PSORT Prediction and iPSORT Prediction (http://psort.hgc.jp/form.html) programs. The theoretical molecular mass and pI as well as the binding and transmembrane domains were estimated through the http://www. expasy.org site.

\subsection{Quantitative Real Time PCR ( $q R T-P C R)$}

Quantitative Real Time PCR was performed for the study of the expression of the GalLDH gene in fruits, leaves, flowers and stems of pepper plants of the cultivar Vergasa used in this work. RNA $(1 \mu \mathrm{g})$ was used as template for the reverse transcriptase reaction. It was added to a mixture containing $0.5 \mathrm{mM}$ dNTPs, $5 \mathrm{ng} / \mu \mathrm{l}$ oligo $\left(\mathrm{dT}_{23}\right)$ in a volume of $12 \mu \mathrm{l}$. This mix was incubated at $65{ }^{\circ} \mathrm{C}$ and, after $5 \mathrm{~min}$, placed on ice. Afterwards, reaction buffer ( $50 \mathrm{mM}$ Tris- $\mathrm{HCl} \mathrm{pH} \mathrm{8.3,} 3 \mathrm{mM} \mathrm{MgCl}_{2}$, $75 \mathrm{mM} \mathrm{KCl}, 10 \mathrm{mM}$ DTT) and $2 \mathrm{U} / \mu \mathrm{l}$ RnaseOUT ${ }^{\mathrm{TM}}$ (RNAses inhibitor, Invitrogen) were added and incubated at $42{ }^{\circ} \mathrm{C}$ for $2 \mathrm{~min}$. Finally, 10 $\mathrm{U} / \mu \mathrm{l}$ SuperScript ${ }^{\mathrm{TM}}$ II Reverse Transcriptase (Invitrogen) was added in a final reaction volume of $20 \mu \mathrm{l}$. The reaction was carried out at $25^{\circ} \mathrm{C}$ for $10 \mathrm{~min}, 42^{\circ} \mathrm{C}$ for $50 \mathrm{~min}$, followed by a $15 \mathrm{~min}$ step at $75{ }^{\circ} \mathrm{C}$, and then by cooling to $4{ }^{\circ} \mathrm{C}$ for $10 \mathrm{~min}$ cDNA $(1 \mu \mathrm{l})$ was added to a mixture containing reaction buffer $(20 \mathrm{mM}$ Tris- $\mathrm{HCl}, \mathrm{pH} 8.4,50 \mathrm{mM} \mathrm{KCl}$, $1.5 \mathrm{mM} \mathrm{MgCl}_{2}$ ), $200 \mathrm{nM}$ of each primer (Supplementary Table 1), $1 \mathrm{U}$ of DNA polymerase (Platinum ${ }^{\circledR}$ Taq DNA Polymerase, Invitrogen), $0.2 \mathrm{mM}$ dNTPs and $2.5 \mu \mathrm{l}$ SYBR Green I (Molecular Probes; 10,000X concentrate in DMSO). Actin, also cloned partially in our laboratory (AY572427) was used as internal standard, since it did not undergo any change during development and ripening [70]. PCR reactions were carried out in a iCycler thermo-cycler (BioRad). A first step of $3 \mathrm{~min}$ at $95^{\circ} \mathrm{C}$ was followed by 40 cycles of $30 \mathrm{~s}$ at $95^{\circ} \mathrm{C}$ and $30 \mathrm{~s}$ at $67.2^{\circ} \mathrm{C}$, and 1 cycle of $40 \mathrm{~s}$ at $72^{\circ} \mathrm{C}$. For the study of the Melt Curve, it was added to this programme 1 cycle of $1 \mathrm{~min}$ at $95^{\circ} \mathrm{C}$, a second one of $1 \mathrm{~min}$ at $70^{\circ} \mathrm{C}$ and finally 60 cycles of $10 \mathrm{~s}$ at $70^{\circ} \mathrm{C}$.

\subsection{Production of antibody against GalLDH}

The service of polyclonal antibody production from a selected peptide of Sigma-Genosys (Cambridge, UK) was used to obtain the antibody against GalLDH. A peptide of 15 amino acids was synthesized from a pepper GalLDH internal consensed sequence (AY547352, complete cds.) also present in several taxonomically related species. The peptide was DIKKNHKKFLSENKH and corresponds to the residues between Asp262 and His276. The peptide is hydrophilic and contains one predicted $\beta$-turn. The selected peptide was conjugated to a carrier protein, the keyhole limpet hemocyanin $(\mathrm{KLH})$ which is derived from marine mollusks via the thiol group of a cysteine residue added to the C-terminus of the selected peptide using MBS (maleimidobenzoylN-hydroxysuccinimide ester) chemistry. Thus the construction DIKKNHKKFLSENKH-[C]-KLH was used for the immunization of two rabbits according to the protocol of six immunizations per rabbit (Sigma-Genosys, Cambridge, UK).

\subsection{SDS-PAGE and immunoblot analysis}

SDS-PAGE was carried out in $7.5 \%$ acrylamide slab gels as described by [56]. Then, proteins were transferred onto PVDF membranes in a semi-dry Trans-Blot cell (Bio-Rad). For the cross-recognition assays after transfer proteins to membranes, the purified IgG from polyclonal antibodies against GalLDH (dilution 1:100) was utilized. For 
the immunodetection in membranes, a goat anti-rabbit IgG-horseradish peroxidase conjugate (BioRad) as the secondary antibody and an enhanced chemiluminescence kit (Clarity ${ }^{\mathrm{TM}}$ Western ECL substrate, BioRad) were used.

For the immune cross-reactivity assays previous to enzyme activity measurements, samples were incubated at $4{ }^{\circ} \mathrm{C}$ overnight with different dilutions of the antibody against the 15 -aminoacid peptide located at the internal sequence of the pepper GalLDH.

\subsection{Determination of $L$-ascorbic acid content}

In the assay of ascorbate concentration in distinct plant organs (leaves, flowers, stems, and green and red fruits), the $\alpha, \alpha^{\prime}$-dipyridyl method was basically followed [76]. Plant materials were prepared with $5 \%(\mathrm{w} / \mathrm{v})$ meta-phosphoric acid in a ratio $1: 3.33(\mathrm{w} / \mathrm{v})$. After treatment with dithiothreitol, samples were incubated with $4 \%$ (w/v) $\alpha, \alpha^{\prime}-$ dipyridyl and the absorbance of the mixtures measured at $525 \mathrm{~nm}$. Obtained values were applied to a standard curve built with commercial ascorbic acid (10-60 $\mu \mathrm{M})$ also prepared in meta-phosphoric acid.

For the measurement of ascorbate content in the assays of NO treatment, the method followed was a modification of the one reported previously in our laboratory for glutathione determination [3]. Pericarp tissues were first ground with liquid nitrogen, and then $0.4 \mathrm{~g}$ of powdered samples were homogenized with $1.3 \mathrm{ml} 0.1 \mathrm{~N} \mathrm{HCl}$. Samples were centrifuged at $15,000 \mathrm{~g}$ for $15 \mathrm{~min}$ at $4^{\circ} \mathrm{C}$ and supernatants were filtered through $0.22 \mu \mathrm{m}$ polyvinylidene fluoride filters. Samples were analyzed by liquid chromatography-electrospray/mass spectrometry (HPLC-ES/MS) using an Allience 2695 HPLC system connected to a Micromass Quattro micro API triple quadrupole mass spectrometer both obtained from the Waters Corporation. HPLC was carried out using an Atlantis ${ }^{\circledast} \mathrm{T} 33 \mu \mathrm{m} 2.1 \times 100 \mathrm{~mm}$ Column obtained from the Waters Corporation. For the instrument control, data collection, analysis and management, the MassLynx 4.1 software package was used. The ascorbic acid concentration was calculated using an external standard and expressed as mg ascorbic acid per $100 \mathrm{~g}$ of fresh weight (FW). All operations were done at $4{ }^{\circ} \mathrm{C}$ and protected from light to avoid potential degradation of the analytes.

\subsection{L-galactono-1,4-lactone dehydrogenase activity assay. Treatment with a peroxynitrite donor (SIN-1) and a nitric oxide donor (GSNO)}

L-galactono-1,4-lactone dehydrogenase (GalLDH; EC 1.3.2.3) activity was measured at $25{ }^{\circ} \mathrm{C}$ according to the method of [75] after slight modifications. The reaction mixture consisted of enzyme extract, $0.1 \mathrm{mM} \mathrm{KCN}, 85 \mu \mathrm{M}$ cytochrome $c$, and $4.2 \mathrm{mM}$ L-galactono-1,4lactone (L-GalL) in $50 \mathrm{mM}$ Tris-HCl buffer ( $\mathrm{pH}$ 8.4). The increase in the absorbance at $550 \mathrm{~nm}$ was followed immediately after the addition of L-GalL. A molar coefficient value of $21.3 \mathrm{mM}^{-1} \mathrm{~cm}^{-1}$ for the reduced form of cyt $c$ was used.

For the nitration and the $S$-nitrosylation assays, before performing the enzyme activities, samples of pepper fruit crude extracts were previously incubated with 3-morpholino-sydnonimine (SIN-1) and $S$ nitrosoglutahione (GSNO). SIN-1 has been shown to generate peroxynitrite $\left(\mathrm{ONOO}^{-}\right)$, a protein-nitrating compound [17,26,30]. Thus, pepper samples were incubated at $25^{\circ} \mathrm{C}$ for $30 \mathrm{~min}$ with increasing concentrations ( $0-5 \mathrm{mM}$ ) of SIN-1 (Calbiochem) freshly made before use. As NO donor, GSNO was used since it is considered a physiological NO donor and it has been previously demonstrated to mediate the protein $S$-nitrosylation (also named as $S$-nitrosation) in plant samples $[16,17]$. For treatments with GSNO, freshly made before use, pepper samples were incubated with $0.5 \mathrm{mM}$ and $2 \mathrm{mM}$ GSNO at $25^{\circ}$ for $30 \mathrm{~min}$ and protected from light [16]. As control, samples were incubated with $0.5 \mathrm{mM}$ and $2 \mathrm{mM} \mathrm{GSH}$, taking into account that GSNO is moderately stable since it decomposes to NO and reduced glutathione (GSH) with a second order rate constant of $3 \times 10^{-4} \mathrm{M}^{-1} \mathrm{~s}$
${ }^{-1}$ [81], In all cases, the samples were passed through NAP-10 columns to avoid any potential interference in the activity assay.

Proteins were quantified by the method of [15] with bovine serum albumin as standard.

\subsection{Statistical analysis}

To analyze the statistical significance between means, the results were subjected to the Student's $t$ - test in all assays. In data from plant organs, statistics was only applied to compare means between green and red fruits. In assays of treatment with exogenous NO gas, values in treated fruits $(+\mathrm{NO})$ were analyzed with respect to untreated (Control) ones. In the experiments where the GalLDH activity was assayed in the presence of different amounts of SIN-1, GSNO and GSH, values at each concentration were compared independently with those obtained in the absence of these compounds (0).

\section{Results}

\subsection{Molecular and immunological characterization of L-galatono- 1,4-lactone dehydrogenase from pepper fruits}

The size of the GalLDH full-length cDNA sequence represented 1836 nucleotides long, with a $5^{\prime}$-unstranslated region of 56 nucleotides, an open reading frame of 1758 nucleotides for the entire protein coding region, and a $3^{\prime}$-non-coding region of 22 nucleotides. In Supplementary Fig 2 the deduced amino acid primary structure, based on the nucleotide sequence obtained after full cloning of the GalLDH, is depicted. The full clone encoded a polypeptide of 586 amino acid residues showing $88 \%$ identity with the one reported for Nicotiana tabacum (Ref. NP_0013127251, 587 amino acids) and that from Lycopersicum esculentum (Ref. BAC11758, 588 amino acids) (Supplementary Fig 2). A phylogenetic tree of several GalLDHs reported from higher plants was built. The closest related GalLDH genes were those from species of the Solanaceae family (Capsicum, Solanum and Nicotiana; Suplementary Fig. 3). The sequence was deposited in databases (NCBI, Ref. AY547352). The full polypeptide sequence contained a signal peptide of 37 amino acids at the $\mathrm{N}$ terminus (Met1-Pro37) typical of mitochondria, as it has been described in other plant species [48,77] and the mature protein consisted of 549 amino acids once the targeting signal is removed upon entrance into the organelle. The sequence was used to determine the theoretical molecular properties of pepper GalLDH thus rendering a molecular mass of $62.2 \mathrm{kDa}$ and an isoelectric point of 6.4 (Supplementary Table 2). Furthermore, this GalLDH of pepper fruits showed several binding domains: one for FAD binding (FAD-binding4); a second one for binding to FAD/FMN dehydrogenases (GlcD); and the last one for binding to some UDP-N-acetylmuramate dehydrogenases (MurB) (Fig. 1A). This is an unstable enzyme according to its stability coefficient of 43.24 (Supplementary Table 2).

The hydrophobic analysis according to the GalLDH amino acid sequence showed a hydrophobicity index of 0.481 (Supplementary Table 2) and the presence of at least one transmembrane helix (Fig. 1). Some tools obtained from www.expasy.org were used in this study. The Transmembrane Helices based on the Hidden Markov Model (TMHMM, CBS, Denmark) showed a main transmembrane domain between the residues Tyr46-Pro65 (Fig. 1B). In that case, the amino acids Thr38-Lys 45 would be facing to the mithochondrial matrix and the rest of the protein (amino acids Phe66-Gln586) would be towards the intermembrane space of the mitochondrion. Although other 2-4 fragments could be potentially transmembrane regions, according to the hydrophobic profile, these last domains have less than $5 \%$ of probability to be a transmembrane helix. The same pattern of transmembrane domains was deduced from the Dense Alignment Surface (DAS) Model (Fig. 1C).

An antibody against a consensus internal amino acid sequence of 

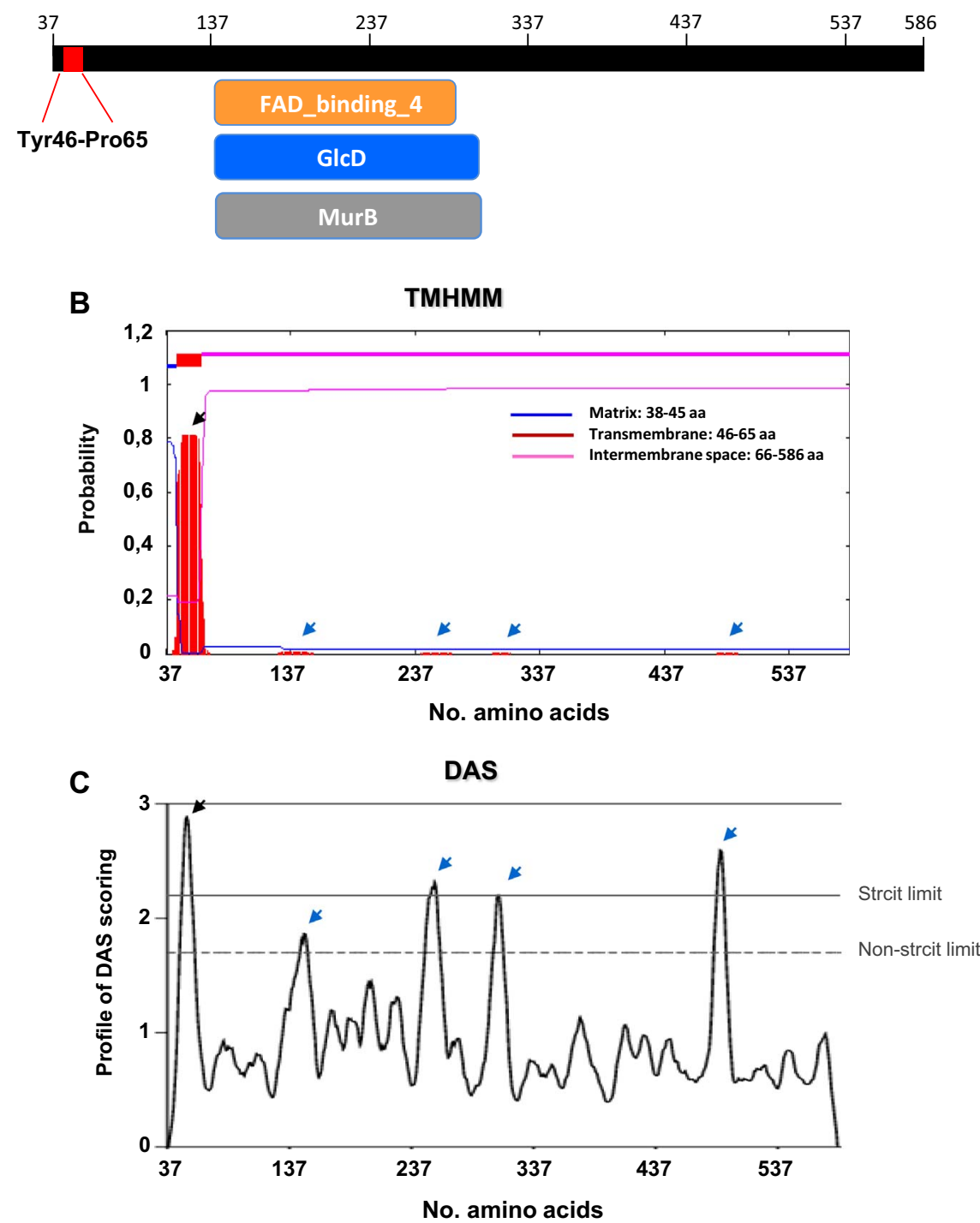

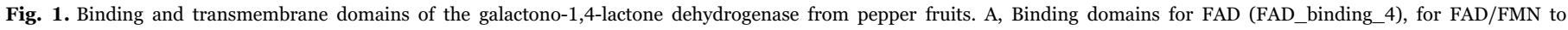

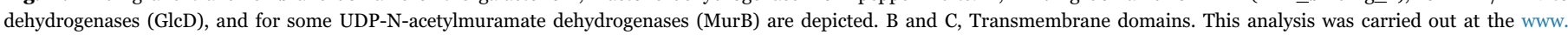

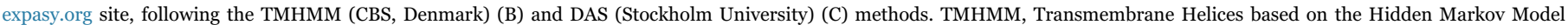

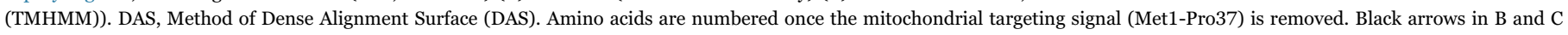
indicate the identified transmembrane domain, whereas blue arrows depict domains with low score to be transmembranal.

the protein was raised in rabbits, and the analysis with crude extracts from pepper fruits provide one unique band of $56 \mathrm{kDa}$ both in green and red fruits (Fig. 2A). To test whether the antibody interacted with the enzyme function, the activity of GalLDH in the presence of increasing antibody concentrations was determined. As shown in Fig. 2B, the enzyme activity decreased as the concentration of the antibody in the assay conditions was raised.

\subsection{Role of GalLDH in the physiology of pepper plants}

Once the GalLDH from fruits was characterized, its pattern of both enzyme activity and gene expression was investigated in different pepper organs and at fruit ripening. Thus, leaves, flowers, stem and pepper fruits at immature (green) and mature (red) stages were analyzed. Fig. 3A depicts the data obtained after measuring GalLDH activity in those organs where the higher values were obtained in fruits and stem. No significant differences were detected between green and red fruits (Student's $t$-test). Conversely, when the expression of GalLDH was studied by real time in the plant organs, an opposite profile was found with the highest expression being observed in leaves and flowers and the lowest values in fruits and stems (Fig. 3B). Regarding to ascorbate content, the highest concentrations were detected in both types of fruits, green and red, with a slight but not significant increase in red peppers (Fig. 3C). As it is depicted in this figure the most remarkable parallelism among the parameters analyzed was the profiles of GalLDH activity and ascorbate concentration in fruits, either green or red.

\subsection{Ascorbic acid in pepper fruits treated with NO}

In a recent paper, it was reported that an NO-enriched atmosphere delayed ripening of pepper fruits, and this could be accompanied by alterations in the pattern of some antioxidants [18]. In the present work, the effect in the ascorbate levels from pepper fruits subjected to an NO-enriched atmosphere (5 ppm) was studied. As it is observed in Fig. 4A, this parameter significantly increased about $42 \%$ in fruits treated with NO with respect to untreated materials. This profile was well correlated with that of GalLDH enzyme activity which showed a 
A Western blotting

Anti-GalLDH
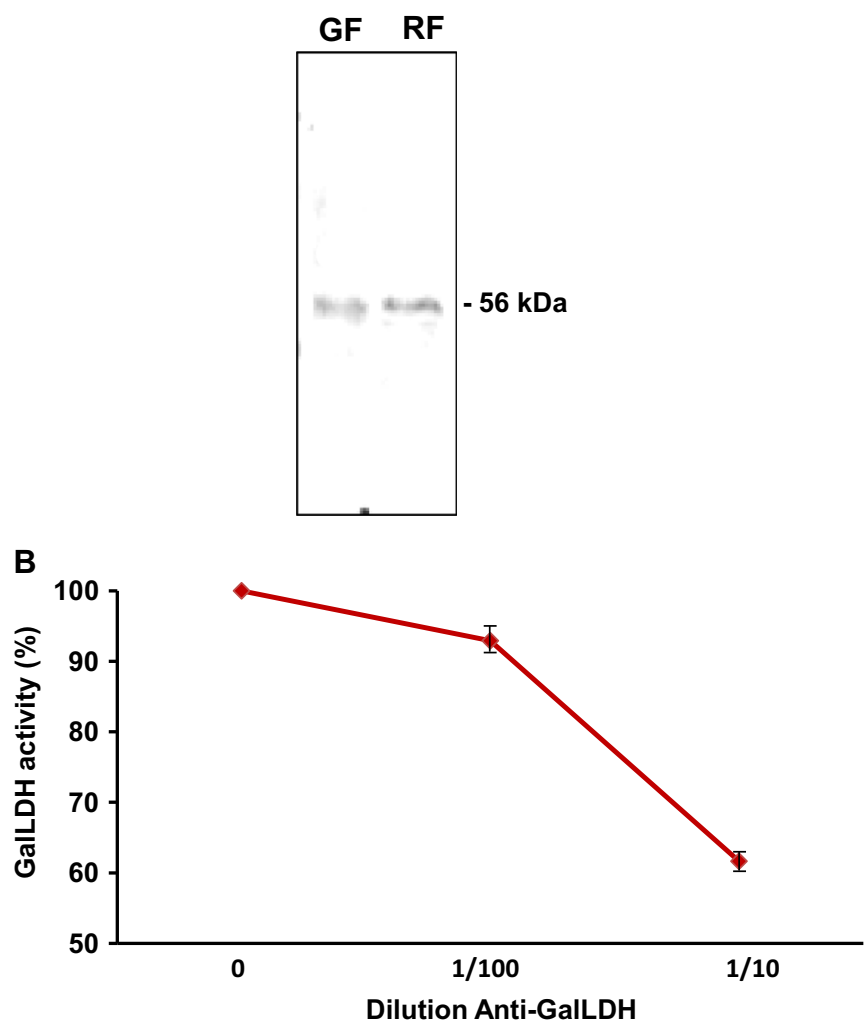

Fig. 2. Immunological characterization of galactono-1,4-lactone dehydrogenase from pepper fruits. A, Western blotting was assayed using an antibody raised against an internal consensed sequence consisting in 15 amino acids. GF, green fruit; RF, red fruit. $\mathrm{B}$, GalLDH activity assayed in crude extracts from red fruits in the presence of different antibody dilutions. Activity was expressed as percentage \pm SEM of the activity measured in the absence of the antibody (100\%) after three independent determinations.

noteworthy enhancement 3-fold as a result of the treatment with NO (Fig. 4B) and also with the expression of the GalLDH gene which was drastically induced about 13 -fold after the incubation with $\mathrm{NO}$, as observed after qRT-PCR analysis (Fig. 4C).

\subsection{Modulation of GalLDH by reactive nitrogen species}

Ripening of pepper fruits is characterized by higher levels of nitrated proteins than those detected in green immature fruits, and this event was reverted by incubation of fruits with a NO-enriched atmosphere. This RNS-mediated post-translational modification was possibly responsible for the lower catalase activity found in red fruits [18]. To investigate its potential modulation by RNS, the GalLDH activity from pepper fruits were assayed in the presence of several RNS sources. Thus, incubation of pepper crude extracts with increasing concentrations of SIN-1 (a peroxynitrite donor) did not modify GalLDH activity significantly (Fig. 5A). Similarly, $S$-nitrosoglutathione (GSNO, an NO donor) did not affect the enzyme activity either (Fig. 5B). Nevertheless, the enzyme activity was significantly inhibited by $60 \%$ with both concentration of reduced glutathione (GSH) (Fig. 5C).
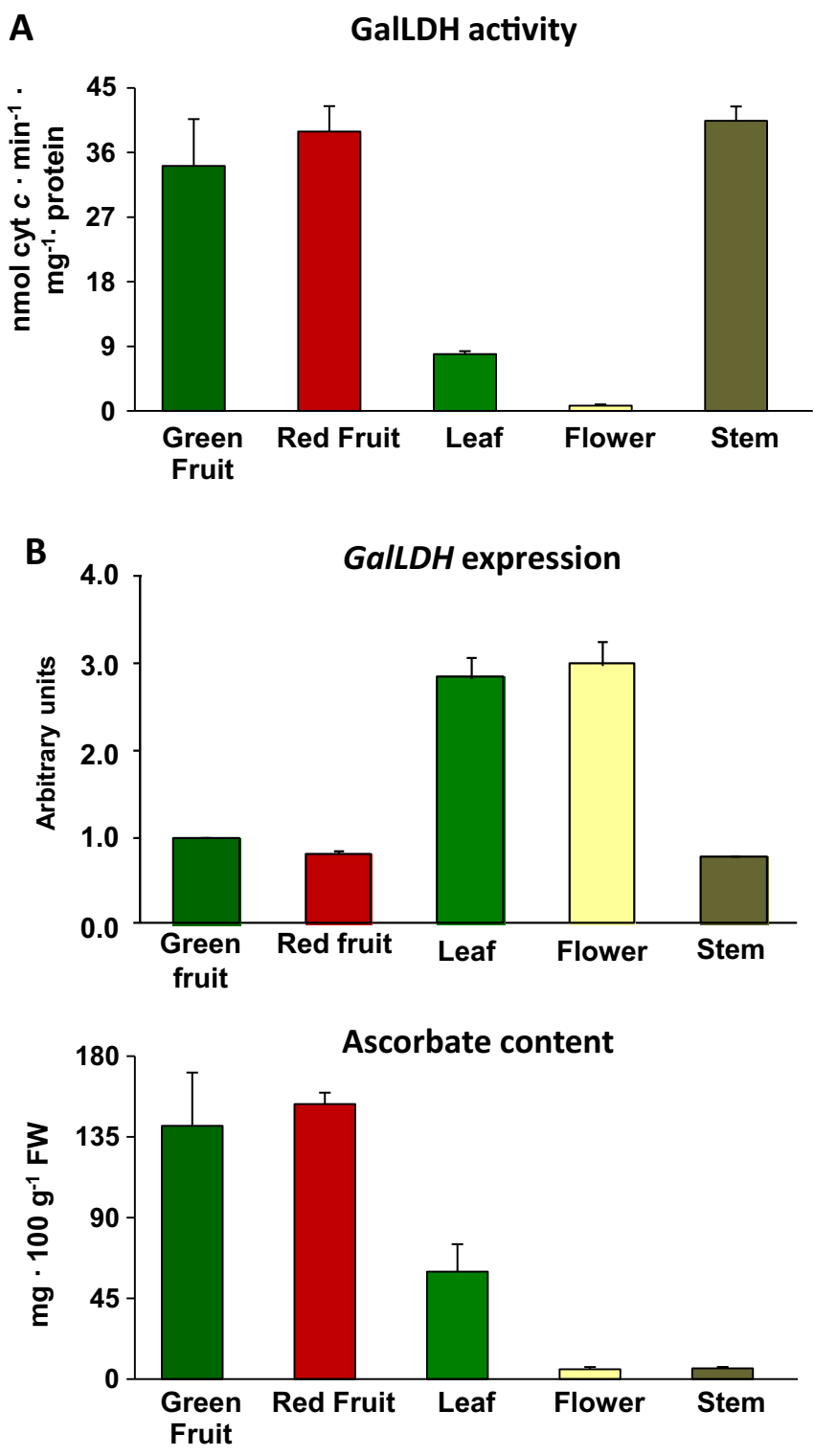

Fig. 3. Galactono-1,4-lactone dehydrogenase activity and gene expression and ascorbate content in different organs of pepper plants. A, GalLDH activity. B, GalLDH gene expression determined by qRT-PCR and quantified considering the reference value (1) to green fruit. C, ascorbate content determined by the $\alpha$, a'-dipyridyl method. Values represent means of three independent experiments \pm SEM. Student's $t$-test was only applied for comparison of means between green and red fruits, and no significant differences were observed. (For interpretation of the references to color in this figure legend, the reader is referred to the web version of this article.)

\section{Discussion}

4.1. GalLDH from pepper fruits contains a mitochondrial targeting signal and one transmembrane domain at the $N$-terminus

Due to its crucial role in the ascorbate biosynthesis, the GalLDH from pepper fruits was cloned, the full sequence obtained, some theoretical molecular properties deduced and a polyclonal antibody against a conserved internal amino acid sequence raised. The amino acid sequence shared high similarities with other GalLDHs reported earlier from Solanaceae species, such as those from tobacco $(N$. tabacum; [105]) and tomato (L. esculentum; [82]). In most cases the monomeric form of GalLDH consisting of about 580-590 amino acids (including the mitochondrial targeting signal) folds giving rise to a polypeptide size of around $56 \mathrm{kDa}[105,12,48,82]$. This size was similar 

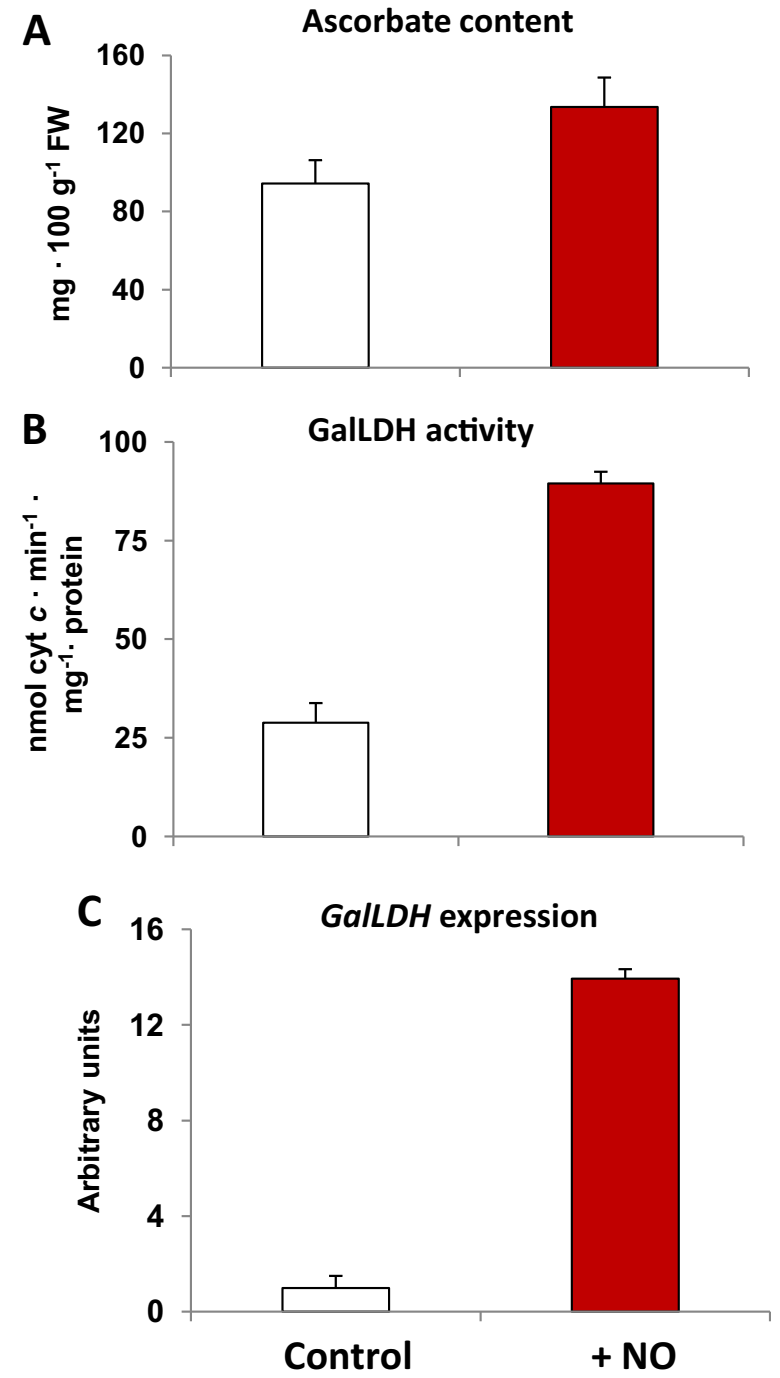

Fig. 4. Effect of treatment with exogenous NO gas on the ascorbate content, and GalLDH enzyme activity and gene expression of pepper fruits. Fruits were subjected to treatment with $5 \mathrm{ppm} \mathrm{NO}$, then maintained at room temperature for $10 \mathrm{~d}$, and crude extracts were prepared for analyses as described in Materials and methods. Values represent means of three independent experiments \pm SEM. Differences between untreated (Control) and NO-treated $(+\mathrm{NO})$ plants were statistically significant (Student's $t$ test, $\mathrm{P} \geq 0.01 ; \mathrm{n}=3$ ).

to that obtained in both green and red pepper fruits after immunoblotting assays.

GalLDH has been reported to be located at the mitochondrial inner membrane [87] where it takes part of an $850 \mathrm{kDa}$ structure associated to the respiratory NADH dehydrogenase complex (complex I). There, GalLDH is integrated into two protein subcomplexes of about 470 and $420 \mathrm{kDa}$, and it has been proved that this protein is necessary for the complex I formation acting as an assembly factor [14,84,85]. In pepper fruits, by differential and density gradient centrifugation approaches, the localization of GalLDH in isolated mitochondria was described some years ago [54]. According to our data on the hydrophobicity profile, GalLDH from pepper fruits would be attached to the mitochondrial membrane through, at least, a very short transmembrane domain of 20 amino acids, with the rest of the protein structure being peripheral (Fig. 6), although up to four additional potential regions could be also involved in the membrane binding. Nevertheless, this issue needs further investigation since reports on this question have indicated both the presence of several membrane-spanning regions but also a peripheral emplacement $[12,48,61,84,87]$. The structural and functional association with complex I reported elsewhere $[84,85]$
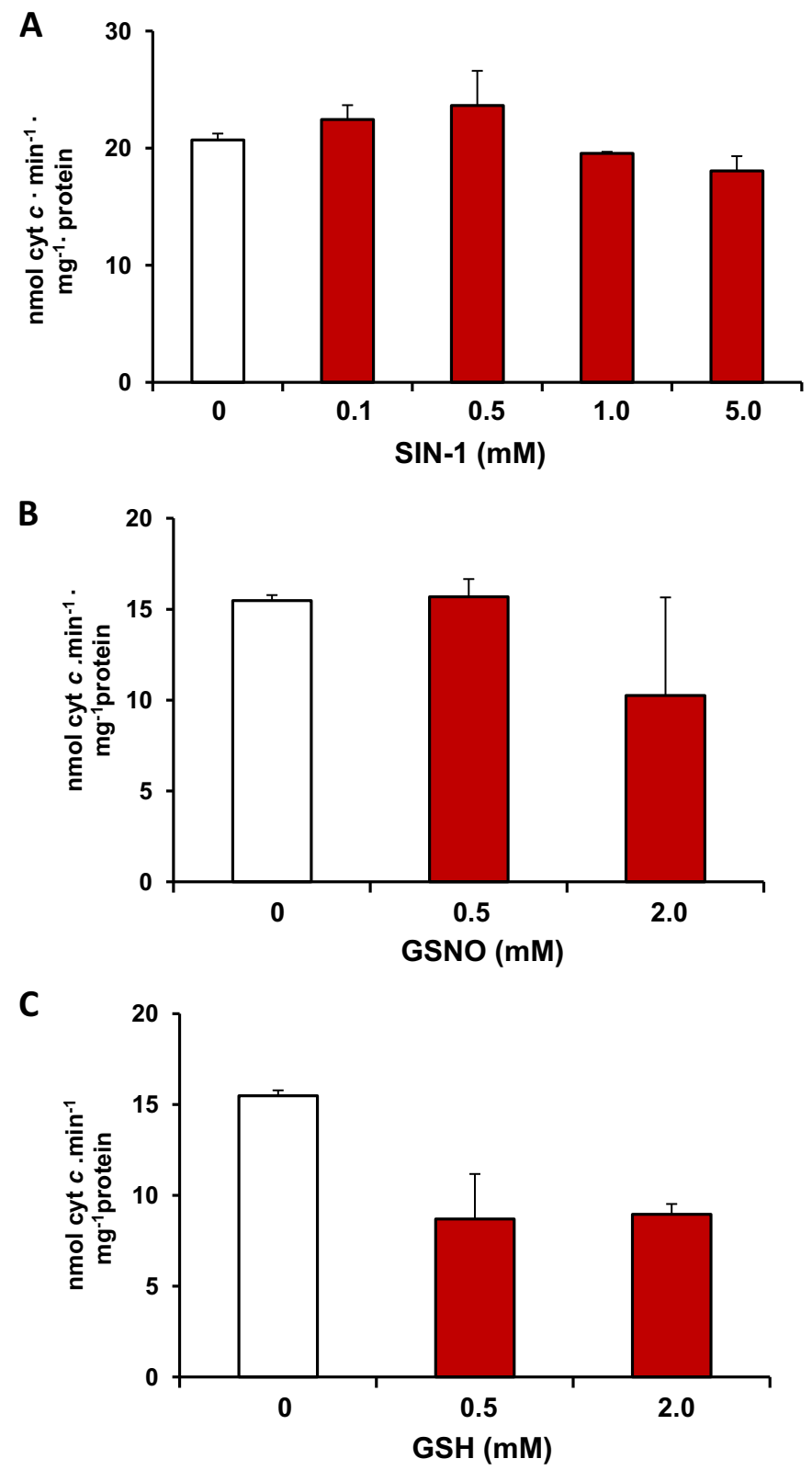

Fig. 5. In vitro assays of galactono-1,4-lactone dehydrogenase activity from pepper fruits under nitration and nitrosylation conditions. GalLDH activity was assayed in the presence of different concentrations of A) 3-morpholino-sydnonimine (SIN-1, a peroxynitrite donor), B) $S$-nitrosoglutahione (GSNO, an NO donor) and C) reduced glutathione (GSH). Values represent means of three independent experiments \pm SEM. Differences among samples treated either with SIN-1 and GSNO were not statistically significant. Treatment of samples with GSH $\geq 0.5 \mathrm{mM}$ provoked significant activity decreases (Student's $t$-test, $\mathrm{P} \geq 0.005 ; \mathrm{n}=3$ ).

would be strengthened by the presence of the FAD-, GlcD- and MurB-binding domains at the N-terminus of the protein sequence. The presence of a flavin cofactor bound to the N-terminus is a shared feature of GalDLHs and other similar aldonolactone oxidoreductases in plants [1]. This steric conformation would allow a closer connection of GalLDH with cytochrome $c$ for the donation of electrons from the galactone-1,4-lactone. In fact, oxidized cytochrome $c$ has been demonstrated to be an electron acceptor of the GalLDH activity $[1,13,14,73]$. Besides, according to our proposed model with the protein anchored by a short domain to the mitochondrial membrane (Fig. 6), it could be hypothesized that GalLDH might have a pivotal role which allows the interaction with several neighboring respiratory oxidases. 


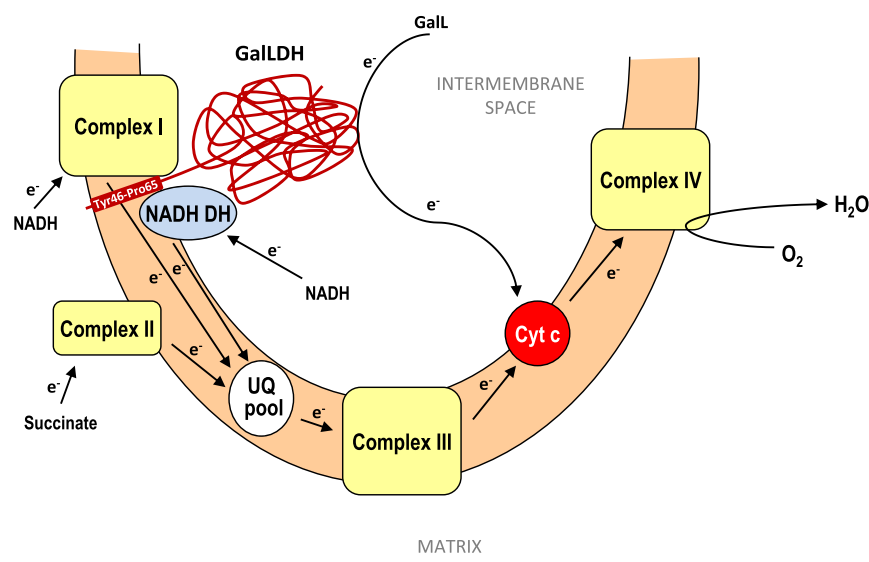

Fig. 6. Electron fluxes in the mitochondria inner membrane in pepper fruits. Complexes I, II, III and IV from the mitochondrial electron transfer chain are depicted. GalLDH, galactono-1,4-lactone dehydrogenase. GalL, galactono-1,4-lactone. NADH DH, dehydrogenase associated to Complex I. UQ pool, ubiquinone pool. Cyt c, cytochrome c. GalLDH contains a transmembrane domain (Tyr46-Pro65) and is able to provide electrons directly to cytochrome $\mathrm{c}$ for reduction of oxygen at the Complex IV site.

\subsection{GalLDH is a key player in the physiology of pepper plants}

The different patterns displayed by the expression of the GalLDH gene and the enzyme activity suggest that GalLDH is a key modulation point of the physiology of pepper plants. Thus, besides the posttranscriptional regulation occurring when fruits were subjected to NO treatment as indicated above, another type of control either at translational or post-translational level seems to take place in the transition from flowering stage to fruit setting, and in the ascorbate metabolism in leaves and shoots. Hence, an accumulation of GalLDH transcripts may undergo in flowers, which are then translated into the respective protein once the fruit is set, to directly synthesize ascorbate in fruits where it plays essential roles [80]. Nevertheless, ascorbate is a small molecule which can move among tissues, and, although pepper fruits have the capacity to synthesize this metabolite due to GalLDH activity, this antioxidant is ubiquitous and can be also provided by other sources, including leaves and shoots $[14,40,42,67,68,95]$. This capacity of ascorbate to be mobile could also help to explain the discrepancy among the profiles observed in the GalLDH activity and gene expression and the ascorbate concentrations in the distinct organs studied.

The constant expression of the GalLDH gene during development and ripening of pepper fruits would allow continuous turnover of the enzyme, since, as it is reported above, GalLDH is an unstable protein, and this contributes to maintain and even increase the ascorbate levels. This enzyme has also an important role during development and fruit ripening of tomato [10,71], melon [82], orange [106], acerola [9], and strawberry [36], among others.

On the other hand, this is not the only limitation step on the ascorbate biosynthesis in pepper fruits. As a matter of fact, steps upstream of the pathway including the production of GDP-mannose and/or L-galactose-1P have been also reported to be key regulatory points. These stages involve the participation of the enzymes GDP-Dmannose pyrophosphorylase (GMP, VTC1) and GDP-L-galactose phosphorylase (GGP, VTC2), respectively. Arabidopsis mutants lacking these genes (vtc1 and $v t c 2)$ are not viable [14,20,37,5,64].

\subsection{GalLDH from pepper fruits is (post)-transcriptionally regulated but does not undergo RNS-mediated post-translational modifications}

So far, the direct incidence of NO on the metabolism of antioxidants has been little studied in plants. Furthermore, the modulation of the levels of antioxidant molecules, such as ascorbate, by NO/RNS has been scarcely addressed, perhaps null attention paid, in crop plants.
This issue arouses interest in species such as pepper whose ascorbate metabolism is fundamental at ripening [80], but also because the direct application of NO gas to fruits promotes delay of ripening and a potential modulation of the enzymatic antioxidant catalase [18]. One potential target to investigate the modulation of ascorbate levels by $\mathrm{NO} / \mathrm{RNS}$ is the galactono-1,4-lactone dehydrogenase (GalLDH) with the aim to assessing if the protein undergoes post-translational modifications (PTM) promoted by RNS. In this work, the study of the effect of NO gas in the ascorbate levels in pepper fruits was addressed and the possible nitration/nitrosylation patterns underwent by the GalLDH was achieved.

Our results indicated that the direct treatment with NO gas led to significant increases of ascorbate contents (40\%) in pepper fruits. This is, to our knowledge, the first report on this issue and its relevance not only comes from a plant molecular point of view, but also since pepper is one of the most consumed vegetable worldwide. Ascorbate content and biosynthesis in higher plants is influenced by light $[14,42,88,94]$ and varies during development, senescence [12], germination [78], fruit ripening $[14,2,54,80,82]$ and flowering [11], thus indicating that the redox state of the cell plays a fundamental role in these processes $[69,102]$. Thus, respiration can control ascorbate synthesis in plants and for its optimum biosynthesis is necessary an electron flux through the complex I of the mitochondrial electron transport chain [73]. The GDP-mannose-3,5-epimerase, which is a possible regulation point in the biosynthetic pathway of the ascorbate in plants, is sensible to the redox state of the cell, being inhibited by NAD(P)H [102]. L-galactose dehydrogenase (GalDH), another key enzyme upstream of the ascorbate biosynthesis, has been also demonstrated to be regulated by reduced ascorbate and not by the oxidized form, dehydroascorbate, thus indicating the importance of the redox conditions for the functioning of the route [72]. Similarly, as our in vitro experiments on GalLDH activity in the presence of GSH show, the ascorbate levels in pepper fruits also depend on the redox chemical surrounding of the GalLDH, since this enzyme activity was inhibited by GSH. However, more research is necessary on this respect under our experimental conditions.

On the other hand, NO has been involved in plant growth and development, as well as in seed germination, primary and lateral root growth, flowering, pollen tube growth regulation, fruit ripening, senescence, defence response and abiotic stress [34,4,58,86]. Accordingly, in many of these coincident cases, ascorbate and NO perhaps interplay between them to favor an appropriate plant response.

NO has been reported to modulate physiological processes through PTMs mediated by RNS thus participating in cellular signaling events ([18,24,25,27,31,50,83]). Most RNS-mediated PTMs include binding to metal centers, nitrosylation of thiol and amine groups, and nitration of tyrosine and other amino acids [43]. In our plant model, the higher ascorbate content displayed by fruits treated with NO gas seems to be partially regulated at transcriptional and/or post-transcripitional levels rather than by post-translational events, at least with regard to those PTMs operating in the GalLDH through RNS. Thus, whereas the greater transcript levels and enzyme activity values found for GalLDH could be responsible for the obtained ascorbate pattern after exposure to NO gas, in vitro assays proved that the enzyme was unaffected by either nitration or nitrosylation reactions. Thus far, no data has been reported on the stability of GalLDH under the RNS derived modification assayed in this work. However, other key points of the route, as those reported above (GMP, GGP, and GalDH), need to be investigated to obtain an overall overview of the ascorbate biosynthesis regulation in pepper fruits.

\section{Concluding remarks}

Ascorbate is a very important molecule for the physiology of plants but also for human nutrition. In fact, the main source of ascorbate for 
humans resides in fruits and vegetables, pepper fruits being one of the most vitamin $\mathrm{C}$ enriched produce consumed worldwide. Gaining knowledge on how plants can be domesticated to supply as much nutrients as possible without poisoning and degrading the environment is part of the agri-food sector nowadays. The regulation of the ascorbate levels in the natural vitamin sources by studying its synthesis, through the investigation of the GalLDH and other enzymes upstream of the pathway, is a key point in this great task. In this work, contribution to understand the molecular properties of GalLDH and its regulation in pepper fruits has been provided. However, more questions have to be addressed to fully obtain a picture of ascorbate in this human food. Answer to questions such as whether this is the only ascorbate biosynthetic pathway in pepper fruits or not (for a full review, see [14]), or how the recycling routes (mainly the ascorbate-glutathione cycle) contribute to the ascorbate pool at each fruit stage, or how the degradation proceeds and which metabolites involve this catabolism, or, finally, how the prevailing environmental conditions influences the ascorbate content have to be addressed, taking into consideration that all those circumstances depend on the pepper types and varieties as it was already proposed [70]. Under this perspective, the results presented in this work indicate that GalLDH is an important step in the modulation of the ascorbate biosynthesis and suggest that it could be potentially used for biotechnological purposes to increase the vitamin C levels in pepper fruits.

\section{Acknowledgements}

This work has been supported by the ERDF-cofinanced grant AGL2015-65104-P from the Ministry of Economy and Competitiveness, Spain. MRR acknowledges an FPI contract (BES2012-055904) from the Ministry of Economy and Competitiveness, Spain. The quantification of ascorbate levels by HPLC-MS was achieved at the Scientific Instrumentation Service, Estación Experimental del Zaidín, CSIC, Granada, Spain. The technical assistance of Carmelo Ruiz, María Jesús Campos, Beatriz Sánchez-Calvo and Elena SánchezRomero is acknowledged.

\section{Appendix A. Supporting information}

Supplementary data associated with this article can be found in the online version at doi:10.1016/j.redox.2017.02.009.

\section{References}

[1] S.I. Aboobucker, A. Lorence, Recent progress on the characterization of aldonolactone oxidoreductases, Plant Physiol. Biochem. 98 (2016) 171-185.

[2] F. Agius, R. González-Lamothe, J.L. Caballero, J. Muñoz-Blanco, M.A. Botella, V. Valpuesta, Engineering increased vitamin C levels in plants by overexpression of a D-galacturonic acid reductase, Nat. Biotechnol. 21 (2003) 177-181.

[3] M. Airaki, L. Sánchez-Moreno, M. Leterrier, J.B. Barroso, J.M. Palma, F.J. Corpas, Detection and quantification of S-nitrosoglutathione (GSNO) in pepper (Capsicum annuum L.) plant organs by LC-ES/MS, Plant Cell Physiol. 52 (2011) 2006-2015.

[4] M. Airaki, M. Leterrier, R. Valderrama, M. Chaki, J.C. Begara-Morales, et al., Spatial and temporal regulation of the metabolism of reactive oxygen and nitrogen species during the early development of pepper (Capsicum annuum) seedlings, Ann. Bot. 116 (2015) 679-693.

[5] M. Alhagdow, F. Mounet, L. Gilbert, A. Nunes-Nesi, V. García, D. Just, J. Petit, B. Beauvoit, A.R. Fernie, C. Rothan, P. Baldet, Silencing of the mitochondrial ascorbate synthesizing enzyme L-galactono-1,4-lactone dehydrogenase affects plant and fruit development in tomato, Plant Physiol. 145 (2007) 1408-1422.

[6] H.M. An, W.G. Fan, L.G. Chen, S. Asgher, Q.L. Liu, Molecular characterization and expression of L-galactono-1,4-lactone dehydrogenase and L-ascrobic acid accumulation during fruit development in Rosa roxburghii, J. Hort. Sci. Biotech. 82 (2007) 627-635.

[7] O. Arrigoni, M.C. De Tullio, The role of ascorbic acid in cell metabolism: between gene-directed functions and unpredictable chemical reactions, J. Plant Physiol. 157 (2000) 481-488.

[8] K. Asada, Production and scavenging of reactive oxygen species in chloroplasts and their functions, Plan Physiol. 141 (2006) 391-396.

[9] A. Badejo, H. Eltelib, K. Fukunaga, Y. Fujikawa, M. Esaka, Increase in ascorbate content of transgenic tobacco plants overexpressing the acerola (Malpighia glabra) phosphomannomutase gene, Plant Cell Physiol. 50 (2009) 423-428.

[10] A.A. Badejo, K. Wada, Y. Gao, T. Maruta, Y. Sawa, et al., Translocation and the alternative D-galacturonate pathway contribute to increasing the ascorbate level in ripening tomato fruits together with the D-mannose/L-galactose pathway, $\mathrm{J}$. Exp. Bot. 63 (2012) 229-239.

[11] C. Barth, M. De Tullio, P.L. Conklin, The role of ascorbic acid in the control of flowering time and the onset of senescence, J. Exp. Bot. 57 (2006) 1657-1665.

[12] C.G. Bartoli, G.M. Pastori, C.H. Foyer, Ascorbate biosynthesis in mitochondria is linked to the electron transport chain between complexes III and IV, Plant Physiol. 123 (2000) 335-343.

[13] C.G. Bartoli, J. Yu, F. Gómez, L. Fernández, L. McIntosh, C.H. Foyer, Interrelationships between light and respiration in the control of ascorbic acid synthesis and accumulation in Arabidopsis thaliana leaves, J. Exp. Bot. 57 (2006) 1621-1631.

[14] C.G. Bartoli, M.E. Senn, G.E. Gergoff Grozef, Physiological processes contributing to the synthesis of ascorbic acid in plants, in: D.K. Gupta, J.M. Palma, F.J. Corpas (Eds.), Redox State as a Central Regulator ofPlant-Cell Stress Responses, Springer International Publishing, 2016, pp. 71-92.

[15] M.M. Bradford, A rapid and sensitive method for the quantitation of microgram quantities of protein utilizing the principle of protein-dye binding, Anal. Biochem. 72 (1976) 706-710.

[16] J.C. Begara-Morales, B. Sanchez-Calvo, M. Chaki, R. Valderrama, C. Mata-Perez, et al., Dual regulation of cytosolic ascorbate peroxidase (APX) by tyrosine nitration and S-nitrosylation, J. Exp. Bot. 65 (2014) 527-553.

[17] J.C. Begara-Morales, B. Sanchez-Calvo, M. Chaki, C. Mata-Perez, R. Valderrama, et al., Differential molecular response of monodehydroascorbate reductase and glutathione reductase by nitration and S-nitrosylation, J. Exp. Bot. 66 (2015) 5983-5996.

[18] M. Chaki, P. Álvarez, de Morales, C. Ruiz, J.C. Begara-Morales, J.B. Barroso, F.J. Corpas, J.M. Palma, Ripening of pepper (Capsicum annuum) fruit is characterized by an enhancement of protein tyrosine nitration, Ann. Bot. 116 (2015) 637-647.

[19] Z. Chen, D.R. Gallie, The ascorbic acid redox state controls guard cell signalling and stomatal movement, Plant Cell. 16 (2004) 1143-1162.

[20] P.L. Conklin, S.R. Norris, G.L. Wheeler, E.H. Williams, N. Smirnoff, R.L. Last, Genetic evidence for the role of GDP-mannose in plant ascorbic acid (vitamin C) biosynthesis, Proc. Natl. Acad. Sci. USA 96 (1999) 4198-4203.

[21] P.L. Conklin, Recent advances in the role and biosynthesis of ascorbic acid in plants, Plant, Cell Environ. 24 (2001) 382-394.

[22] P.L. Conklin, C. Barth, Ascorbic acid, a familiar small molecule intertwined in the response of plants to ozone, pathogens and the onset of senescence, Plant Cell Environ. 27 (2004) 959-970.

[23] P.L. Conklin, S. Gatzek, G. Wheeler, J. Dowdle, M. Raymond, et al., Arabidopsis thaliana VTC4 encodes L-galactose-1-P phosphatase, a plant ascorbic acid biosynthesis enzyme, J. Biol. Chem. 281 (2006) 15662-15670.

[24] F.J. Corpas, A. Carreras, R. Valderrama, M. Chaki, J.M. Palma, et al., Reactive nitrogen species and nitrosative stress in plants, Plant Stress 1 (2007) 37-41.

[25] F.J. Corpas, L.A. del Río, J.B. Barroso, Post-translational modifications mediated by reactive nitrogen species: nitrosative stress responses or components of signal transduction pathways?, Plant Signal. Behav. 3 (2008) 301-303.

[26] F.J. Corpas, J.D. Alché, J.B. Barroso, Current overview of S-nitrosoglutathione (GSNO) in higher plants, Front. Plant Sci. 4 (2013) 126.

[27] F.J. Corpas, J.B. Barroso, NADPH-generating dehydrogenases: their role in the mechanism of protection against nitro-oxidative stress induced by adverse environmental conditions, Front. Environ. Sci. 2 (2014) 55.

[28] F.J. Corpas, D.K. Gupta, J.M. Palma, Production sites of reactive oxygen species (ROS) in organelles from plant cells, in: D.K. Gupta, F.J. Corpas, J.M. Palma (Eds.), Reactive oxygen species and oxidative damage in plants under stress, Springer International Publishing Switzerland, 2015, pp. 1-20.

[29] C. Cronje, G.M. George, A.R. Fernie, J. Bekker, J. Kossmann, R. Bauer, Manipulation of L-ascorbic acid biosynthesis pathways in Solanum lycopersicum: elevated GDP-mannose pyrophosphorylase activity enhances L-ascorbate levels in red fruit, Planta 235 (2012) 553-564.

[30] A. Daiber, M. Bachschmid, J.S. Beckman, T. Munzel, V. Ullrich, The impact of metal catalysis on protein tyrosine nitration by peroxynitrite, Biochem. Biophys. Res. Commun. 317 (2004) 873-881.

[31] I. Dalle-Donne, A. Scaloni, D. Giustarini, E. Cavarra, G. Tell, et al., Proteins as biomarkers of oxidative/nitrosative stress in diseases: the contribution of redox proteomics, Mass Spectrom. Rev. 24 (2005) 55-99.

[32] M.W. Davey, M. Van Montagu, D. Inzé, M. Sanmartin, A. Kanellis, N. Smirnoff, I.J.J. Benzie, J.J. Strain, D. Favell, J. Fletcher, Plant L-ascorbic acid: chemistry, function, metabolism, bioavailability and effects of processing, J. Sci. Food Agric 80 (2000) 825-860.

[33] M.C. De Tullio, C. Paciolla, F. Dalla Veechia, N. Rascio, S. D'Emerico, L. De Gara, R. Liso, O. Arrigoni, Changes in onion root development induced by the inhibition of peptidyl-prolyl hydroxylase and influence of the ascorbate system on cell division and elongation, Planta 209 (1999) 424-434.

[34] L.A. del Río, F.J. Corpas, J.B. Barroso, Nitric oxide and nitric oxide synthase activity in plants, Phytochemistry 65 (2004) 783-792.

[35] L.A. del Río, Peroxisomes as a cellular source of reactive nitrogen species signal molecules, Arch. Biochem. Biophys. 506 (2011) 1-11.

[36] J.R.O. do Nascimento, B.K. Higuchi, M.L.P.A. Gómez, R.A. Oshiro, F.M. Lajolo, 1ascorbate biosynthesis in strawberries: L-Galactono-1,4-lactone dehydrogenase expression during fruit development and ripening, Postharvest Biol. Technol. 38 (2005) 34-42.

[37] J. Dowdle, T. Ishikawa, S. Gatzek, S. Rolinski, N. Smirnoff, Two genes in 
Arabidopsis thaliana encoding GDP-L-galactose phosphorylase are required for ascorbate biosynthesis and seedling viability, Plant J. 52 (2007) 673-689.

[38] C.H. Foyer, G. Noctor, Redox homeostasis and antioxidant signalling: a metabolic interface between stress perception and physiological responses, Plant Cell 17 (2005) 1866-1875.

[39] C.H. Foyer, G. Noctor, Ascorbate and glutathione: the heart of redox hub, Plant Physiol. 155 (2011) 2-18.

[40] V.R. Franceschi, N.M. Tarlyn, L-ascorbic acid is accumulated in source leaf phloem and transported to sink tissues in plants, Plant Physiol. 130 (2002) 649-656.

[41] M.A. Frohman, M.K. Dush, G.R. Martin, Rapid production of full-length cDNAs from rare transcripts: amplification using a single gene-specific oligonucleotide primer, Proc. Natl. Acad. Sci. USA 85 (1988) 8998-9002.

[42] H. Gautier, C. Massot, R. Stevens, S. Sérino, M. Génard, Regulation of tomato fruit ascorbate content is more highly dependent on fruit irradiance than leaf irradiance, Ann. Bot. 103 (2009) 495-504.

[43] A.J. Gow, C.R. Farkouh, D.A. Munson, M.A. Posencheg, H. Ischiropoulos, Biological significance of nitric oxide-mediated protein modifications, Am. J. Physiol. Lung Cell. Mol. Physiol. 287 (2004) L262-L268.

[44] B. Halliwell, J.M.C. Gutteridge, Free Radicals in Biology and Medicine, 5th ed, Oxford University Press, Oxford, 2015.

[45] M. Hervás, Q. Bashir, N.G.H. Leferink, P. Ferreira, B. Moreno-Beltrán, et al., Communication between L-galactono-1,4-lactone dehydrogenase and cytochrome c, FEBS J. 280 (2013) 1830-1840.

[46] N. Horemans, C.H. Foyer, G. Potters, H. Asard, Ascorbate function and associated transport systems in plants, Plant Physiol. Biochem. 38 (2000) 531-540.

[47] N. Horemans, C.H. Foyer, H. Asard, Transport and action of ascorbate at the plant plasma membrane, Trends Plant Sci. 5 (2000) 263-267.

[48] T. Imai, S. Karita, G. Shiratori, M. Hattori, T. Nunome, K. Oba, M. Hirai Lgalactono-gamma-lactone, dehydrogenase from sweet potato: purification and cDNA sequence analysis, Plant Cell Physiol. 39 (1998) 1350-1358.

[49] T. Imai, Y. Ban, S. Terakami, T. Yamamoto, T. Moriguchi, L-ascorbate biosynthesis in peach: cloning of six L-galactose pathway-related genes and their expression during peach fruit development, Physiol. Plant. 136 (2009) 139-149.

[50] H. Ischiropoulos, A. Gow, Pathophysiological functions of nitric oxide-mediated protein modifications, Toxicology 208 (2005) 299-303.

[51] F.A. Isherwood, L.W. Mapson, Biological synthesis of ascorbic acid: the conversion of derivatives of D-galacturonic acid into L-ascorbic acid by plant extracts, Biochem. J. 64 (1956) 13-22.

[52] T. Ishikawa, J. Dowdle, N. Smirnoff, Progress in manipulating ascorbic acid biosynthesis and accumulation in plants, Physiol. Plant. 126 (2006) 343-355.

[53] A. Jiménez, J.A. Hernández, L.A. del Río, F. Sevilla, Evidence for the presence of ascorbate-glutathione cycle in mitochondria and peroxisomes of pea leaves, Plant Physiol. 114 (1997) 275-284.

[54] A. Jiménez, J.M. Gómez, E. Navarro, F. Sevilla, Changes in the antioxidative systems in mitochondria during ripening of pepper fruits, Plant Physiol. Biochem. 40 (2002) 515-520.

[55] K. Kiuchi, M. Nishikimi, K. Yagi, Purification and characterization of L-gulonolactone oxidase from chicken kidney microsomes, Biochemistry 21 (1982) 5076-5082.

[56] U.K. Laemmli, Cleavage of structural proteins during the assembly of the head of bacteriophage T4, Nature 227 (1970) 680-685.

[57] W. Laing, M. Wright, J. Cooney, S. Bulley, From the cover: the missing step of the L-galactose pathway of ascorbate biosynthesis in plants, an L-galactose guanyltransferase, increases leaf ascorbate content, Proc. Natl. Acad. Sci. USA 104 (2007) 9534-9539.

[58] L. Lamattina, C. García-Mata, M. Graziano, G. Pagnussat, Nitric oxide: the versatility of an extensive signal molecule, Annu. Rev. Plant Biol. 54 (2003) $109-136$.

[59] L. Lamattina, C. García-Mata, Gasotransmitter in Plants. The Rise of New Paradigm in Cell Signaling. Signaling and Communication in Plants, Springer International Publishing Switzerland, 2016.

[60] M. Landi, M. Fambrini, A. Basile, M. Salvini, L. Guidi, C. Pugliesi, Overexpression of L-galactono-1,4-lactone dehydrogenase (L-GalLDH) gene correlates with increased ascorbate concentration and reduced browning in leaves of Lactuca sativa L. after cutting, Plant Cell, Tissue Organ Cult. 123 (2015) 109-120.

[61] N.G. Leferink, W.A. van den Berg, W.J. van Berkel, L-Galactono-gamma-lactone dehydrogenase from Arabidopsis thaliana, a flavoprotein involved in vitamin C biosynthesis, FEBS J. 275 (2008) 713-726.

[62] M. Li, F. Ma, J. Liu, J. Li, Shading the whole vines during young fruit development decreases ascorbate accumulation in kiwi, Physiol. Plant. 140 (2010) 225-237.

[63] C. Linster, T. Gómez, K. Christensen, L. Adler, B. Young, et al., Arabidopsis VTC2 Encodes a GDP-L-galactose phosphorylase, the last unknown enzyme in the Smirnoff-Wheeler pathway to ascorbic acid in plants, J. Biol. Chem. 282 (2007) 18879-18885.

[64] C.L. Linster, S.G. Clarke, L-Ascorbate biosynthesis in higher plants: the role of VTC2, Trends Plant Sci. 13 (2008) 567-573.

[65] F. Liu, L. Wang, L. Gu, W. Zhao, H. Su, X. Cheng, Higher transcription levels in ascorbic acid biosynthetic and recycling genes were associated with higher ascorbic acid accumulation in blueberry, Food Chem. 188 (2015) 399-405.

[66] F.A. Loewus, S. Kelly, Identity of L-ascorbic acid formed from D-glucose by the strawberry (Fragaria), Nature 191 (1961) 1059-1061.

[67] A. Lorence, B.I. Chevone, P. Mendes, C.L. Nessler, Myo-inositol oxygenase offers a possible entry point into plant ascorbate biosynthesis, Plant Physiol. 134 (2004) $1200-1205$.

[68] C. Massot, R. Stevens, M. Genard, J.J. Longuenesse, H. Gautier, Light affects ascorbate content and ascorbate-related gene expression in tomato leaves more than in fruits, Planta 235 (2012) 153-163.

[69] R.M. Mateos, D. Bonilla-Valverde, L.A. del Río, J.M. Palma, F.J. Corpas, NADPdehydrogenases from pepper fruits: effect of maturation, Physiol. Plant. 135 (2009) 130-139.

[70] R. Mateos, A. Jiménez, P. Román, F. Romojaro, S. Bacarizo, et al., Antioxidant systems from pepper (Capsicum annuum L.): Involvement in the response to temperature changes in ripe fruits, Int. J. Mol. Sci. 14 (2013) 9556-9580.

[71] I. Mellidou, J. Keulemans, A.K. Kanellis, M.W. Davey, Regulation of fruit ascorbic acid concentrations during ripening in high and low vitamin $\mathrm{C}$ tomato cultivars, BMC Plant Biol. 12 (2012) 239.

[72] T. Mieda, Y. Yabuta, M. Rapolu, T. Motoki, T. Takeda, K. Yoshimura, T. Ishikawa, S. Shigeoka, Feedback inhibition of spinach L-galactose dehydrogenase by Lascorbate, Plant Cell Physiol. 45 (2004) 1271-1279.

[73] A.H. Millar, V. Mittova, G. Kiddle, J.L. Heazlewood, C.G. Bartoli, F.L. Theodoulou, C.H. Foyer, Control of ascorbate synthesis by respiration and its implications for stress responses, Plant Physiol. 133 (2003) 443-447.

[74] M. Nishikimi, B.M. Tolbert, S. Udenfriend, Purification and characterization of Lgulono-gamma-lactone oxidase from rat and goat liver, Arch. Biochem. Biophys. 175 (1976) 427-435.

[75] K. Ôba, S. Ishikawa, M. Nishikawa, H. Mizuno, T. Yamamoto, Purification and properties of L-galactonolactono-y-lactone dehydrogenase, a key enzyme for ascorbic acid biosynthesis, from sweet potato roots, J. Biochem. (Tokyo) 117 (1995) 120-124.

[76] M. Okamura, An improved method for determination of L-ascorbic acid and Ldehydroascorbic acid in blood plasma, Clin. Chim. Acta 103 (1980) 259-268.

[77] J. Østergaard, G. Persiau, M.W. Davey, G. Bauw, M. Van Montagu, Isolation of a cDNA coding for L-galactono-gamma-lactone dehydrogenase, an enzyme involved in the biosynthesis of ascorbic acid in plants, Purif., Charact., cDNA Cloning, Expr. yeast. J. Biol. Chem. 272 (1997) 30009-30016.

[78] J.E. Pallanca, N. Smirnoff, Ascorbic acid metabolism in pea seedlings. A comparison of D-glucosone, L-sorbosone, and L-galactono-1,4-lactone as ascorbate precursors, Plant Physiol. 120 (1999) 453-461.

[79] J.M. Palma, A. Jiménez, F.J. Corpas, R.M. Mateos, M.C. Martí, F. Sevilla, L.A. del Río, Role of ascorbate on the fruit physiology of pepper (Capsium annuum L.), Funct. Plant Sci. Biotechnol. 5 (2011) 56-61.

[80] J.M. Palma, F. Sevilla, A. Jiménez, L.A. del Río, F.J. Corpas, P. Álvarez, de Morales, D.M. Camejo, Physiology of pepper fruit and the metabolism of antioxidants: chloroplasts, mitochondria and peroxisomes, Ann. Bot. 116 (2015) 627-636.

[81] J.W. Park, Reaction of S-nitrosoglutathione with sulfhydryl groups in protein, Biochem. Biophys. Res. Commun. 152 (1988) 916-920.

[82] I. Pateraki, M. Sanmartin, M.S. Kalamaki, B. Gerasopoulos, A.K. Kanellis, Molecular characterization and expression studies during melon fruit development and ripening of L-galactono-1,4-lactone dehydrogenase, J. Exp. Bot. 55 (2004) 1623-1633.

[83] R. Radi, Nitric oxide, oxidants, and protein tyrosine nitration, Proc. Natl. Acad. Sci. USA 101 (2004) 4003-4008.

[84] P. Schertl, S. Sunderhaus, J. Klodmann, G.E. Grozeff, C.G. Bartoli, H.P. Braun, Lgalactono-1,4-lactone dehydrogenase (GLDH) forms part of three subcomplexes of mitochondrial complex I in Arabidopsis thaliana, J. Biol. Chem. 287 (2012) $14412-14419$

[85] J. Schimmeyer, R. Bock, E.H. Meyer, L-Galactono-1,4-lactone dehydrogenase is an assembly factor of the membrane arm of mitochondrial complex I in Arabidopsis, Plant Mol. Biol. 90 (2016) 117-126.

[86] A.D. Shapiro, Nitric oxide signaling in plants. In Plant Hormones, ed. G Litwack pp. 339-398, 2005.

[87] E. Siendones, J.A. González-Reyes, C. Santos-Ocaña, P. Navas, F. Córdoba, Biosynthesis of ascorbic acid in kidney bean. L-galactono-gamma-lactone dehydrogenase is an intrinsic protein located at the mitochondrial inner membrane, Plant Physiol. 120 (1999) 907-912.

[88] N. Smirnoff, Ascorbate biosynthesis and function in photoprotection, Philos Transanctions R. Soc. Lond. B Biol. Sci. 355 (2000) 1455-1464.

[89] N. Smirnoff, G.L. Wheeler, Ascorbic acid in plants: Biosynthesis and function, Crit. Rev. Plant Sci. 19 (2000) 267-290.

[90] N. Smirnoff, J.A. Running, S. Gaztek, Ascorbate biosynthesis: a diversity of pathways, in: H. Asard, J.M. May, N. Smirnoff (Eds.), Vitamin C: Functions and Biochemistry in Animals and Plants, BIOS Scientific Publishers, London, 2004, pp. 7-29.

[91] N. Smirnoff, Antioxidant and Reactive Oxygen Species in Plants, Blackwell Publishing Ltd, Oxford, 2005.

[92] A. Szarka, G. Banhegyi, H. Asard, The inter-relationship of ascorbate transport, metabolism and mitochondrial, plastidic respiration, Antioxid. Redox Signal. 19 (9) (2013) 1036-1044.

[93] K. Tabata, T. Takaoka, M. Esaka, Gene expression of ascorbic acid-related enzymes in tobacco, Phytochemistry 61 (2002) 631-635.

[94] M. Tamaoki, F. Mukai, N. Asai, N. Nakajima, A. Kubo, M. Aono, H. Saji, Lightcontrolled expression of a gene encoding L-galactono-gamma-lactone dehydrogenase which affects ascorbate pool size in Arabidopsis thaliana, Plant Sci. 164 (2003) 1111-1117.

[95] L. Tedone, R. Hancock, S. Alberino, S. Haupt, R. Viola, Long-distance transport of L-ascorbic acid in potato, BMC Plant Biol. 4 (2004) 16.

[96] R.P. Tripathi, B. Singh, S.S. Bisht, J. Pandey, L-Ascorbic acid in organic synthesis: an overview, Curr. Org. Chem. 13 (2009) 99-122.

[97] V. Valpuesta, M.A. Botella, Biosynthesis of L-ascorbic acid in plants: new pathways for an old antioxidant, Trends Plant Sci. 9 (2004) 573-577. 
[98] K. Wang, X. Shao, Y. Gong, F. Xu, H. Wang, Effects of postharvest hot air treatment on gene expression associated with ascorbic acid metabolism in peach fruit, Plant Mol. Biol. Report. 32 (2014) 881-887.

[99] G.L. Wheeler, M.A. Jones, N. Smirnoff, The biosynthetic pathway of vitamin C in higher plants, Nature 393 (1998) 365-369.

[100] G.L. Wheeler, T. Ishikawa, V. Pornsaksit, N. Smirnoff, Evolution of alternative biosynthetic pathways for vitamin C following plastid acquisition in photosynthetic eukaryotes, eLife 4 (2015) e06369.

[101] L.T. Wei, L.N. Wang, Y. Yang, P.F. Wang, T.C. Guol, G.Z. Kang, Abscisic acid enhances tolerance of wheat seedlings to drought and regulates transcript levels of genes encoding ascorbate-glutathione biosynthesis, Front. Plant Sci. 6 (2015) 458.

[102] B.A. Wolucka, M. Van Montagu, GDP-mannose 3',5'-epimerase forms GDP-Lgulose, a putative intermediate for the de novo biosynthesis of vitamin $\mathrm{C}$ in plants, J. Biol. Chem. 278 (2003) 47483-47490.

[103] B.A. Wolucka, M. Van Montagu, The VTC2 cycle and the de novo biosynthesis pathways for vitamin C in plants: an opinion, Photochemistry 68 (2007) 2602-2613.

[104] Y. Xu, X.W. Zhu, Y.L. Chen, Y.Q. Gong, L.W. Liu, Expression profiling of genes involved in ascorbate biosynthesis and recycling during fleshy root development in radish, Plant Physiol. Biochem. 70 (2013) 269-277.

[105] Y. Yabuta, K. Yoshimura, T. Takeda, S. Shigeoka, Molecular characterization of tobacco mitochondrial L-galactono-gamma-lactone dehydrogenase and its expression in Escherichia coli, Plant Cell Physiol. 41 (2000) 666-675.

[106] X.Y. Yang, J.X. Xie, F.F. Wang, J. Zhong, Y.Z. Liu, et al., Comparison of ascorbate metabolism in fruits of two citrus species with obvious difference in ascorbate content in pulp, J. Plant Physiol. 168 (2011) 2196-2205.

[107] X. Yan, X. Zhang, M. Lu, Y. He, H. An, De novo sequencing analysis of the Rosa roxburghii fruit transcriptome reveals putative ascorbate biosynthetic genes and EST-SSR markers, Gene 561 (2015) 54-62.

[108] K. Yoshimura, T. Nakane, S. Kume, Y. Shiomi, T. Maruta, et al., Transient expression analysis revealed the importance of VTC2 expression level in light/ dark regulation of ascorbate biosynthesis in Arabidopsis, Biosci. Biotechnol. Biochem. 78 (2014) 60-66.

[109] L. Zsigmond, B. Tomasskovics, V. Deak, G. Rigo, L. Szabados, et al., Enhanced activity of galactono-1,4-lactone dehydrogenase and ascorbate-glutathione cycle in mitochondria from complex III deficient Arabidopsis, Plant Physiol. Biochem. 49 (2011) 809-815. 